\title{
Radiological Evaluation of Fractures Healing Processing Fixed by Food Grate Stainless Steel Rods in Rabbits
}

\author{
Humam H Nazht ${ }^{1}$, Rania $\mathbf{K}^{2}$ and Sumaya $\mathbf{M}^{2}$ \\ ${ }^{1}$ Surgery and Obstetric Department, College of Veterinary Medicine, University of \\ Baghdad, Iraq \\ ${ }^{2}$ Private veterinary doctors, Iraq \\ *Corresponding author: Humam H Nazht, Department of Surgery and Obstetric, \\ College of Veterinary Medicine, University of Baghdad, Iraq, Tel: 009647901784013; \\ Email: Humam_nazhat@yahoo.com
}

\section{Research Article \\ Volume 4 Issue 3}

Received Date: October 16, 2019

Published Date: December 06, 2019

DOI: $10.23880 /$ oajvsr-16000189

\section{Abstract}

This study was designed to follow up the radiological changes of the fracture healing process of the induced transverse femoral mid shift fracture in rabbits that fixed by food grate stainless steel rods (FGSR). Eight adult local breed rabbits were employed to induce complete transverse mid shift fracture in the femoral bone, under general anesthesia with highly aseptic technique. The fracture fragments fixed with FGSR, the study followed for more than two months by weekly radiographic examination, which revealed, the fracture healing occurs by secondary or indirect bone union, in which the new bone formation can be visible radiographically at the end of $2^{\text {nd }}$ week Post operation (p.o.) around the fractures line which still visible, the callus formation increase in volume and density at the end of $3^{\text {rd }}$ week, at the end of $4^{\text {th }}$ weeks bony bridge formation and disappear of fracture line, at the end of the $6^{\text {th }}$ weeks radiological union occurs and the FGSR removed and remodeling phase started and continuous next week the conclusion the fracture healing processing of the induced fracture in the femoral bones in rabbits which fixed FGSR as internal fixation methods can be determined radiographically.

Keywords: Radiological Evaluation; Transverse femoral mid shift fractures; Food grate stainless steel rods; Radiological union

\section{Introduction}

The fractures are a medical condition with damage in the continuity of the bone, can be result from external or internal high force or stress, or due to bone disease that weaken the bones, such as osteoporosis, bone cancer, or osteogenesis and vascularization impairment [1].
Many trails and efforts were spending for improvements the internal fixation methods and selection of implant of small animals, like pins, wires, screws, plates - rod fixation, and interlocking nails, in the aim of using these methods were for fractures stabilization, minimized trauma of surrounding soft tissue and promote biologic osteosynthesis [2-4]. 


\section{Open Access Journal of Veterinary Science \& Research}

Intramedullary nailing ( IM) fixation has become the stander of treatment for both femoral and tibial shift fractures, the union rate for the femur reach $97 \%$, because of its success, easy and commonly used for fixation, and less traumatic especially in critically ill patient [5,6].

Nazht used the FGSR for the internal fixation of the induced transverse complete fractures in the diaphyseal femoral bone in rabbit, in which he replaced the medical stainless steel pin by the FGSR for more than 10 years since 2007 to 2019 for internal fractures fixation, and got good result in fixation transverse fractures or fixation xeno- bony implantation of both sheep and bovine or even in fixation synthetics scaffold bony nano implantation and awarded patent in 2018 (the author himself) [7].

A fracture can be considered healed if there is, bone continuity of the cortex, a calcified complete bridging callus, no visible fracture line, and stop formation of the hard callus, with high density and smooth borders, and follow-up these event radiographically are important to assess proper alignment and adequate healing of a fracture, and the formation of a callus is one of the characteristic used to follow these features in variable time and size by Archibold [8], Jerry [9].

The fracture healing process begins immediately after the fracture with the inflammatory phase, in which damage to the surrounding blood vessels and tissue leading to a hematoma formation [10]. Inflammatory mediators are released causing inflammatory cells to migrate to the region producing the framework of callus formation [11-14]. This stage lasts 5 to 7 days [14,15] with some overlap into the next phase [12,10]. The hematoma formed in the initial phase serves as a structure in which the callus forms into mature bone. Through the action of growth factors and other proteins, granulation tissue is converted to radiolucent cartilaginous callus. Eventually, this is mineralized by the deposition of calcium salts $[12,14,16,10]$.

The next stage, the reparative phase, is when the callus develops. This stage lasts from 4 to 40 days, composing about $40 \%$ of the healing process time with overlap into the final phase $[12,15]$, Once the calcification occurs, the callus becomes evident radiographically. This woven bone, or periosteal callus, creates an irregular radiographic appearance that is fluffy, amorphous, and biologically plastic [10].
Endosteal callus or intramedullary callus also develops as part of the healing process, this type of callus is usually not visible on $\mathrm{x}$-ray film $[17,18]$.

The last stage of repair is the remodeling phase. This composes about $70 \%$ of the healing time and can last for well over 1 year [10,12]. This phase is characterized by conversion of periosteal callus into lamellar or mature bone [12]. Unnecessary callus is resorbed and trabecular bone produced [19].

The amount of periosteal stripping and time of weight bearing can be contributing factors for callus appears radiographically [18-21]. Frost in (1989) [14] suggests mineralization of long bone fractures takes at least 4 weeks before being evident on radiographs. Doyle and Manaster, [22] cautions that the exact timing of radiographic examination depends on many variables, which include the nature and location of the fracture along with the patient's age.

The aim of present study was radiographic follow up of the fracture healing processing of induced transverse femoral fracture in rabbits, that fixed internally by FGSR.

\section{Materials and Methods}

Eight adult local breed rabbits were employed to induce a transverse mid shift fracture in the femoral bone with highly aseptic technique under general anesthesia by intramuscular administration of both $17 \mathrm{mg} / \mathrm{kg} \mathrm{B.W.} 2 \%$ xylazine hydrochloride and $25 \mathrm{mg} / \mathrm{kg}$ B.W. of $10 \%$ ketamine hydrochloride respectively. The two fragments bones were fixed internally by $2.25-2.5 \mathrm{~mm}$ diameter and $7-8 \mathrm{~cm}$ in length FGSR (awarded patent of stainless steel rods in 2018 for the author himself).

\section{Surgical Operation}

Prepare the lateral aspect of the thigh region, by clipping and shaving the hair, wash with tape water and soap, then disinfect the area by scrapping with $70 \%$ ethyl alcohol, about $4 \mathrm{~cm}$ skin incisions was made at the imaginary line from the great trochanter of the femoral bone and the lateral aspect of the patella, at the groove of the attachments of both the vastus laterals and biceps femoralis muscles, the skin and the subcutaneous tissues was sharply dissected, the fascialata was incised proximal and distal to femoral diaphysis, the femoral muscles were bluntly dissected then the under lined abducted muscle was separated from the femoral diaphysis by fine and 
curved artery forceps, the periostium was incised and the femoral bone was exposed by inserting two scalpels below the femoral bone (Figures $1 \mathrm{~A}$ and $\mathrm{B}$ ), transverse complete fracture was created by electrical saw with dropping sterile normal saline to prevent thermal necrosis (Figures 2A and B), the two bone fragments were fixed with the proper size and length of FGSR, about 2.25 $-2.5 \mathrm{~mm}$ diameter and about $7-8 \mathrm{~cm}$ in length as internal fixation method, apply local antibiotics powder, the femoral muscles and the fascialata were closed by simple continuous suture pattern using 2/0 absorbable suture materials, skin closed by simple interrupted suture pattern using $2 / 0$ non absorbable suture materials (Figures $3 \mathrm{~A}$ and $\mathrm{B}$ ).

\section{Post-0perative Care and Examination}

1. Daily checking the site of operation from complication, swelling, and bleeding

2. Systemic antibiotics lincomycine for 3 days post operation.

3. Remove the suture materials 8 days p.o.

4. The FGSR removed after radiological union.

5. Weekly radiographic examination until the end of two months.
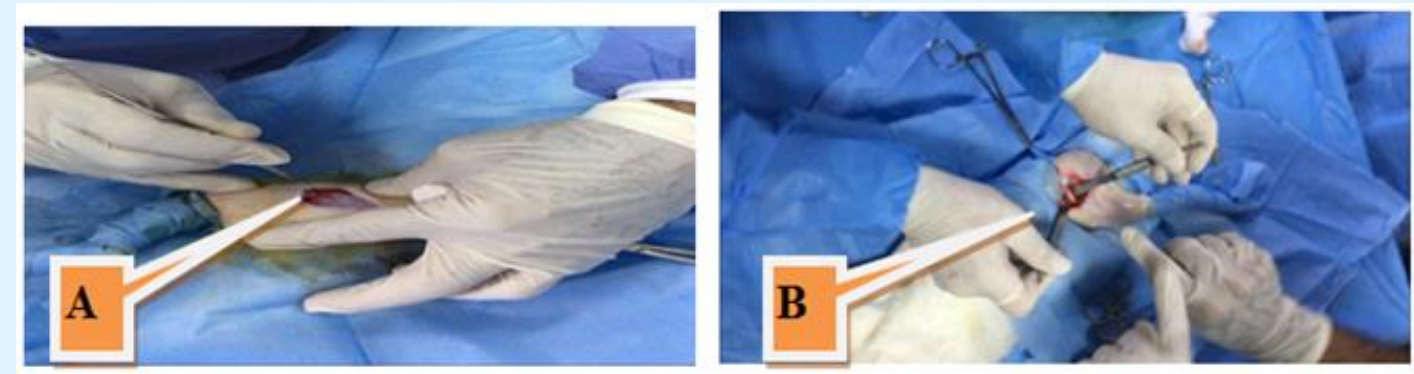

Figure 1: A. Induce surgical incision at the lateral aspect on thigh. B. Expose femoral bone.
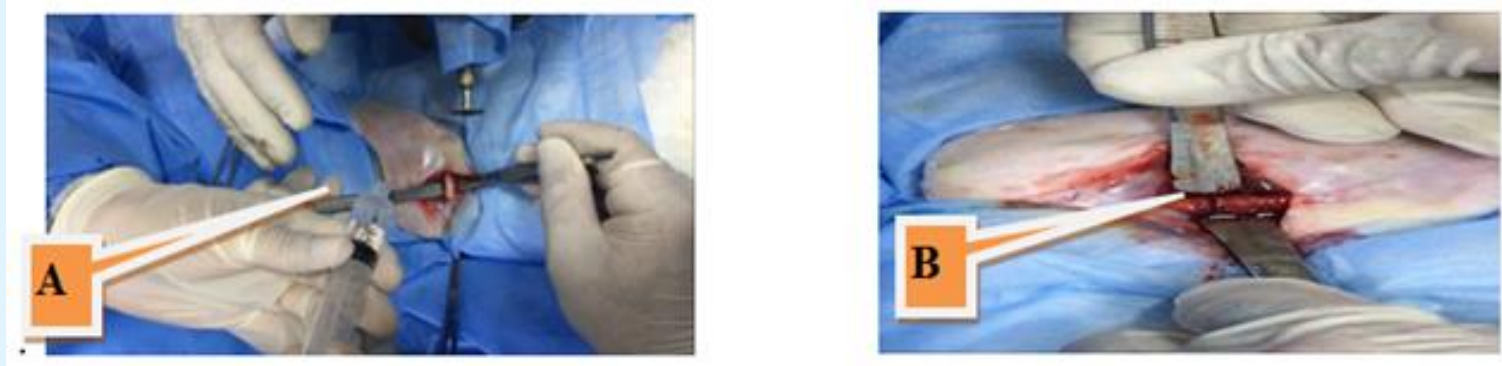

Figure 2: A. Induce fracture by using electrical saw, and dropping normal saline to prevent thermal necrosis of bone; B. create complete transverse midshift femoral fracture.
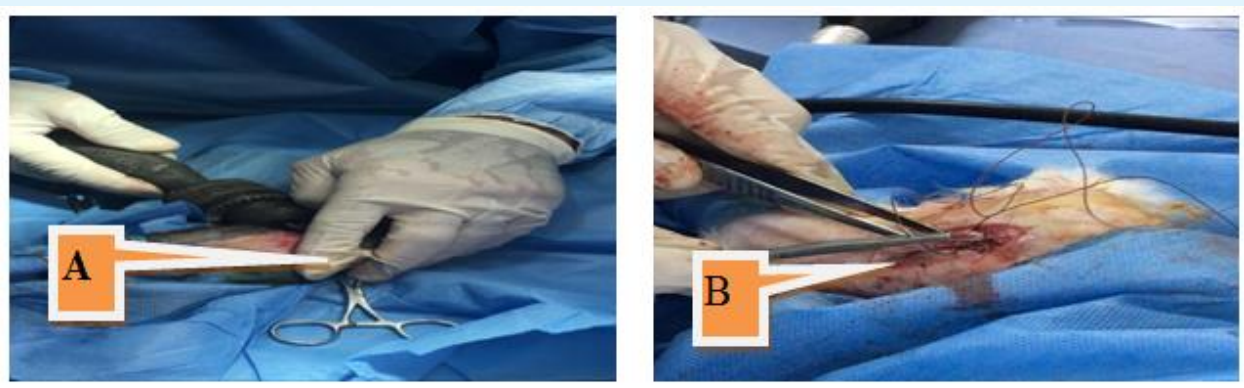

Figure 3: A. insert the FGSR inside the marrow canal for internal fixation using pin chock; B. Close the surgical incision. 


\section{Open Access Journal of Veterinary Science \& Research}

\section{Results}

\section{The Radiographic Finding}

Immediately after induced transverse and Complete fracture: Clear fracture gape that separated the two femoral fragments with sharp end which well-fixed by FGSR that filled about $60-70 \%$ of the marrow canal, no periosteal reaction was visible radiographically along the bone cortex proximal and distal to the fracture line (Figure 4).

- End of first week p.o. The radiographic finding revealed well alignment of the two femoral fracture fragments well fixed by the FGSR, the fracture line still visible with smooth (Figure 5).

$>$ End of second week p.o. The periosteal reaction was visible at the end of the femoral fragments that begins away from the fracture line toward the fracture site; the new bone formation appears low density that formed at the anterior aspect of the proximal segment and the caudal aspect of the distal segments (Figure 6).

$>$ End of third week p.o. Increase in volume and density of the callus formation which created from the proximal and distal segments of the cortex of the femoral bone, and still not cover the fracture line, high sclerotic area at the fracture line (Figure 7).

$>$ End of fourth week p.o. Revealed increase in volume and density of the callus formation, the fracture line disappear, and beginning of the bony bridge formation to union the two fractures fragments, well alignment, well fixed well stable (Figure 8).

$>$ End of sixth week p.o. Stopped formation of the callus new formation around the fracture line with increased density, bony bridge formation and sclerotic area at the site of fracture line, radiological union, with thickening of the cortex (Figure 9).

End of the seventh week p.o. One week after removing the FGSR: Revealed increase the density of the new bone formation with, thickening the endostium and the perostium around the fracture line (Figure 10).

End of two months p.o. Two weeks after the removing FGSR: Show well alignment of the two femoral fragments still thickening the endostium with increased density of the new bone formation (Figure 11).

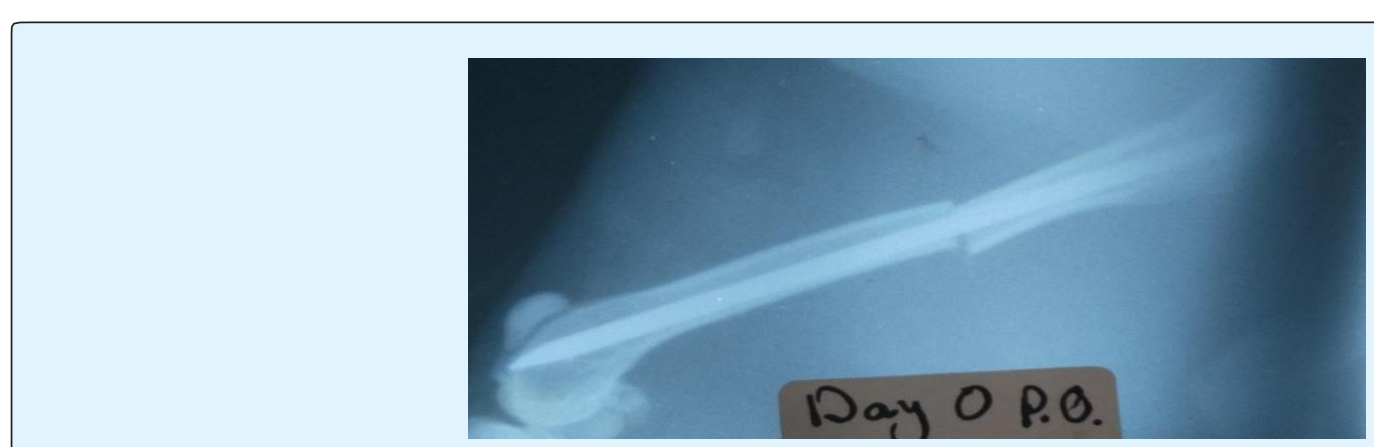

Figure 4: Radiographic image immediately after induced femoral transverse fracture shows well fixation, with visible and sharp end of fracture line.

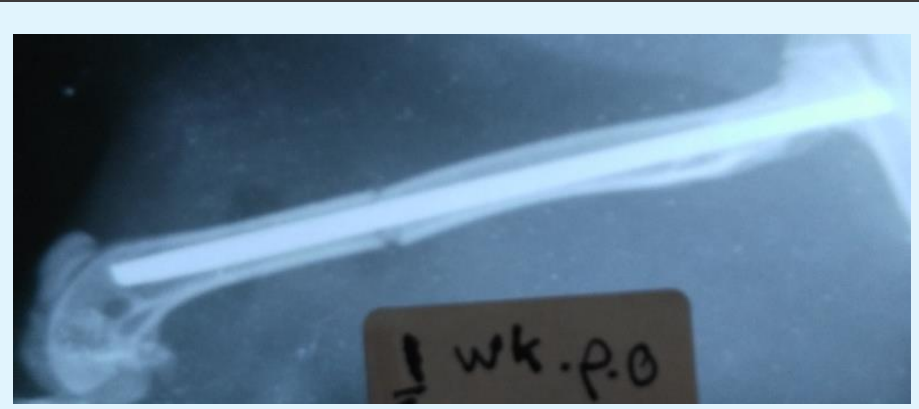

Figure 5: Radiographic finding end of 1st week p.o. revealed, well alignment of the fracture fragments and well-fixed with FGSR, with smooth and still visible fracture line. 


\section{Open Access Journal of Veterinary Science \& Research}

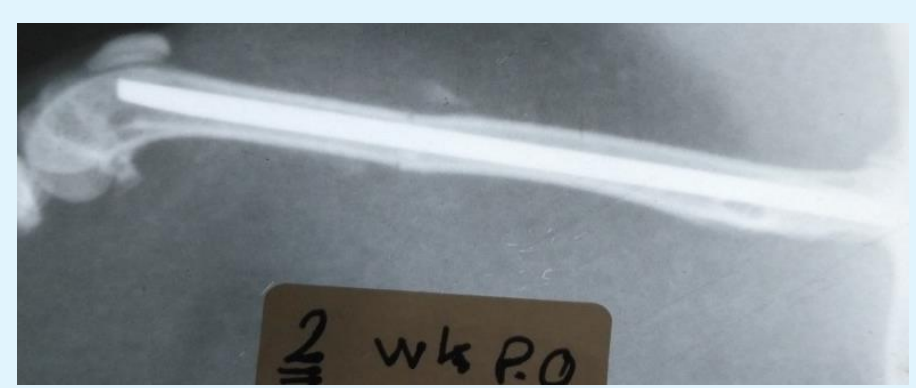

Figure 6: Radiographic image at the end of second week p.o. revealed new bone formation visible radiographically from the cortex of the proximal and distal fragments toward the fracture line, the fracture line still visible with smooth end.

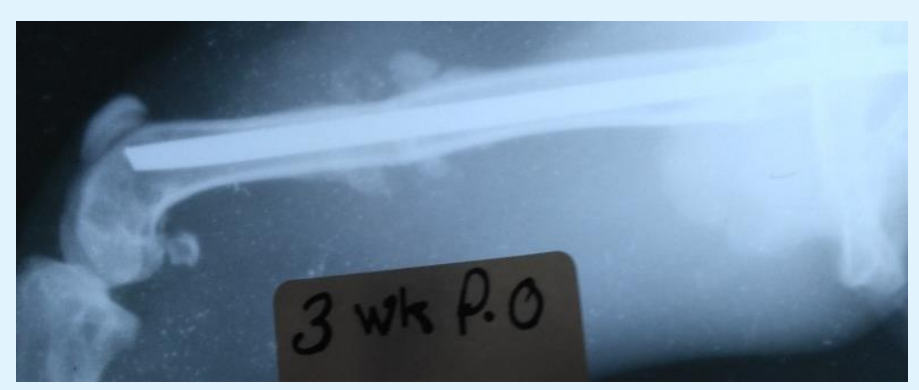

Figure 7: Radiographic image end of the third week p.o. revealed increase in volume and density of the callus formation, with sclerotic area at the fracture line.

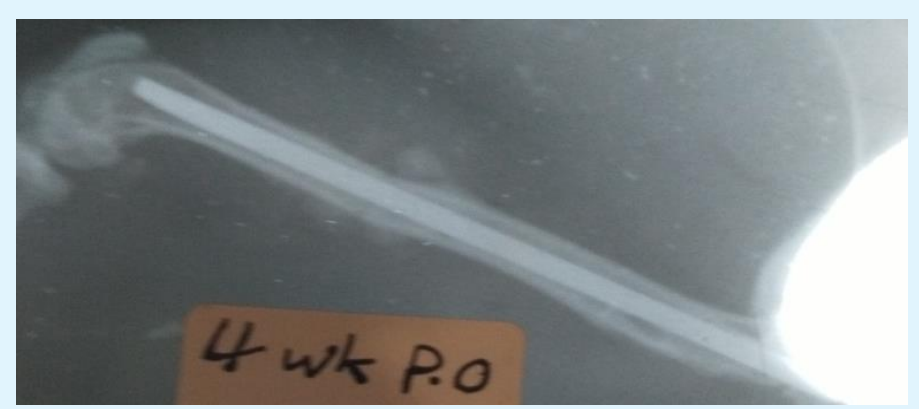

Figure 8: Radiographic image end of the fourth week p.o. revealed increase in volume and density of the new bone formation, the fracture line disappear, and beginning of the bridge formation to union the two fractures fragments.

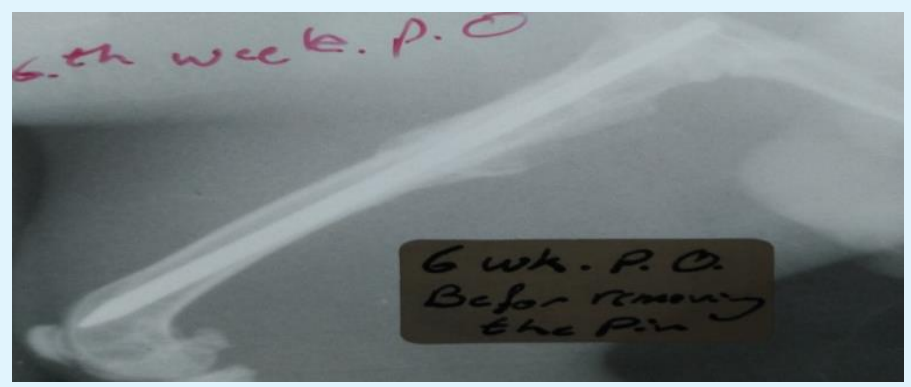

Figure 9: Radiographic image end of sixth week p.o. Revealed radiological union, stopped of the callus formation with high density, the fracture line is disappear, with thickening of the cortex. 


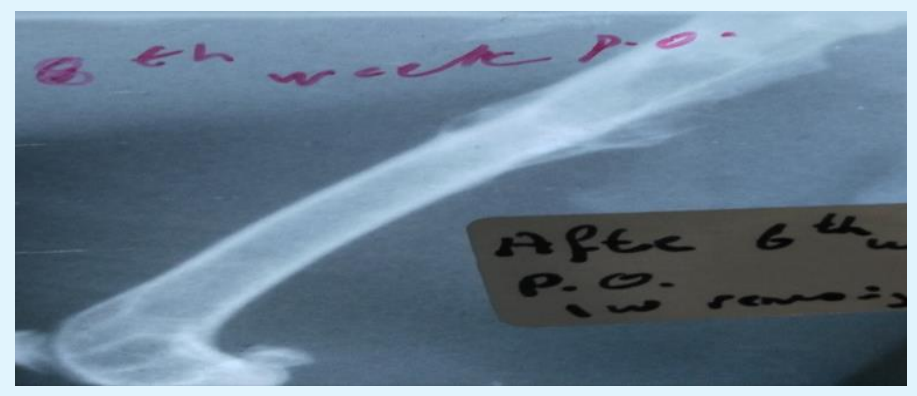

Figure 10: Radiographic image seventh week p.o. one week after removing the FGSR revealed increase density of the new bone formation high sclerotic are at the fracture line thickening of endostium and periosteium.

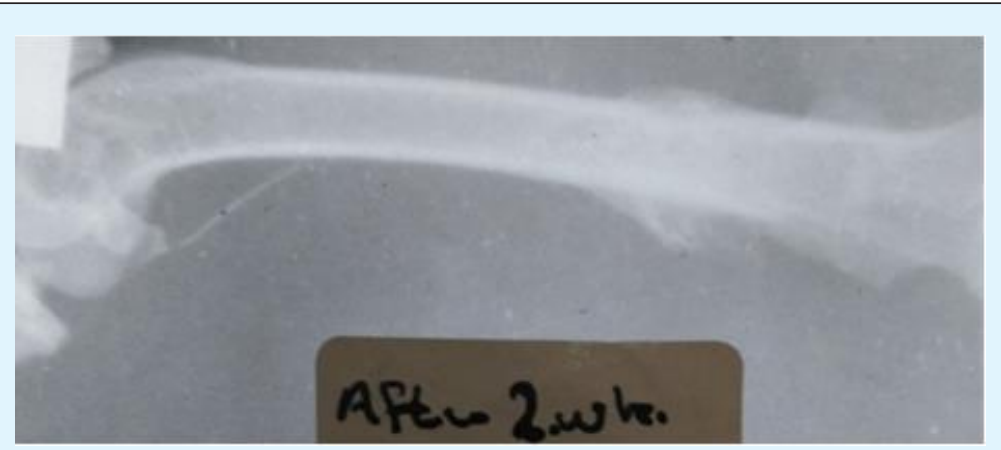

Figure 11: Radiographic image eight week p.o. and two week after the removing FGSR two months p.o. show well alignment of the two femoral fragments thickening endostium with increased density of the new bone formation.

\section{Discussion}

The FGSR which used for the femoral fracture fixation is popular easy to use, gives good results of fixation, strong, stable and lead to callus formation that followed radiographically and the healing by indirect or secondary bony union, and this exactly mentioned by Krettek, et al. [5], Christodoulous, et al. [6] that Fracture healing fixation by pinning is achieved by callus formation by the periosteal reaction outside the fracture line mentioned from Manasterr [23].

At the end of $1^{\text {st }}$ week, no signs of ossification could be found, but at end of $2^{\text {nd }}$ week $p$. o. the periosteal reaction appears radiographically which agree with Ruedi, et al. [24] that the new callus formation can be visible radiographically from 10-14 days p. 0 .

At the end of 3rd week the external callus formation increase in volume and density around the fracture line from proximal and distal parts of the bone away from fracture line, the cortex still not completely incorporated within fracture line and this agree with Thelen, et al. [25].
At the end of $4^{\text {th }}$ week the external hard bony callus bridge formed leading to union the two fractured fragments. This agrees with Manasterr. Who clear that the periosteal was expanded by callus formed from sheath around bone fragments, and lead to a solid union in some simple fractures furthermore, patency of the medullary canal was maintained due to the presence of the intra nails [25-27].

The remolding phase at the end of the $6^{\text {th }}$ week p. 0 . and the next week was started and achieved by homogenous external callus with smooth outer border and stop formation of more callus around the fracture line, the cortex beings to incorporated with the other side and this agree with Lastayo, et al. [26] Who refer that, at 3 months, all fractures radiographically consolidated, but other workers not agree and they pointed that at 6 months, the remodeling process was well process but external callus was still present, and cortical bone was not reconstructed, its quality seemed excellent [2]. A fracture can be considered healed if there is, Bone continuity of the cortex, A calcified and ossified complete bridging callus, no visible fracture line, and stop formation of the hard callus, high density, smooth borders [8,9]. 


\section{Open Access Journal of Veterinary Science \& Research}

Complete healing fracture occurs after 28 days p. 0. which achieved radiologically by radiographic union and produced bridge of hard callus around the fracture gape, disappear the fracture line, while other studies refer the common average healing times of femoral shaft fractures no less than 12 week $[25,27,28]$.

The radiographic finding after using FGSR shows secondary bone healing which achieved by callus formation around fractures line in the end $2^{\text {nd }}$ week p.o. that increase in volume and density at the end of $3^{\text {rd }}$ week, the radiological union occurs with disappears of fracture line $4^{\text {th }}$ and $6^{\text {th }}$ week p.o. and these agree with Ruedi, et al. [24], then remodeling stages continuous which appears as homogenous external callus with smooth border ,stop forming external callus formation [19] with good bone alignment and cortical incorporation [24,27-30].

\section{Conclusion}

Fractures healing processing by using food grate stainless steel rods (FGSR) as internal fixation methods for the induced transverse complete mid shift fracture can be successfully evaluated radiographically.

\section{Recommendation}

1. Estimation alkaline phosphates enzymes level for evaluation.

2. Physical parameters for evaluation the new bone formation.

3. Histopathological examination for evaluation.

4. Histomorphmetric examination for the evaluation.

\section{References}

1. Marshall T, Browner BD (2012) Chapter20: Emergency care of musculoskeletal injuries. In: Courtney M, Towsend Jr, (Eds.), Sabiston textbook of surgery: the biological basis of modern surgical practice, Elsevier, pp: 480-520.

2. Humam H Nazht (1992) The Effect of Prostaglandin (PGF2a) on Fracture Healing in Long Bones: Radiological, Clinical and Histological, Studies, A thesis of M.Sc. College of Vet Med Univ of Baghdad.

3. Humam H Nazht (2000) Effects of Prostaglandin $E_{2}$ on Bone Resorption in the Remodeling Phase of the Femoral Bone Fractures in Rabbits. A thesis of Ph.D. July. College of Vet Med Univ of Baghdad.
4. Stiftler KS (2004) Internal fracture fixation. Clin Tech Small Anim Pract 19(3): 105-113.

5. Krettek C, Miclau T, Blauth M, Lindsey RW, Donow C, et al. (1997) Recurrent rotational deformity of the femur after static locking of intramedullary nails: case reports. J Bone Joint SurgI Br 79(1): 4-8.

6. Krettek C, Miclau T, Blauth M, Lindsey RW, Donow C, Tscherne H (1997) Recurrent Rotational Deformity of the Femur After Static Locking of intramedullary Nails. J Bone Joint Surg Br 79-B: 4-8.

7. Christodoulou A, Terzidis I, Ploumis A, Metsovitis S, Koukoulidis A, et al. (2005) Supracondylar femoral fracture in elderly patients treated with the dynamic condylar serew and the retrograde intramedullary nail: a comparative study of the two methods. Arch orthop Trauma Surg 125(2): 73-79.

8. Humam H Nazht (2019) Using Food Grate Stainless Steel Rods for Internal Fixation of transverse fractures in Rabbits. J Vet Sci Res 4(1): 1-9.

9. Archibald J (1974) Canine Surgery, $2^{\text {nd }}$ (Edn.), American Veterinary Publication, INC, California.

10. Jerry M Owens (1991) Radiographic Interpretation for the small animal clinician.

11. Rockwood CA, Green DP, Bucholz RW (1991) Healing of musculoskeletal tissues, $3^{\text {rd }}$ (Edn.), In: rockwood and Green is Fractures in Adults, JB Lippincott, Philadelphia.

12. Bostrom MP, Asnis P (1998) Transforming growth factor beta in fracture orthop 355(S1): S124-S131.

13. Cruess RL, Dumont J (1975) Current concepts: fracture healing. Can J Surg 18(5): 403-413.

14. Simmons DJ (1985) Alteration of fracture healing perspectives. Clin Orthop Relat Res 200: 100-113.

15. Frost HM (1989) The biology of fracture healing: an overview for clinicians: part I. Clin Orthop 248: 283293.

16. Hulth A (1989) Current concepts of fracture healing. Clin Orthop 249: 265-283.

17. Hendrex RW (1992) Fracture healing. Rogers, In: Radiology of Skeletal Trauma, Churchill Livingstone New York, NY, pp: 203-221. 


\section{Open Access Journal of Veterinary Science \& Research}

18. Juhl, JH (1993) Crummy AB. Traumatic lesions of bones and joint. In: Essentials of Radiologic Imaging, $6^{\text {th }}$ (Edn.), JB Lippincott, Philadelphia, pp: 43-44.

19. Marsh D (1998) Concepts of fracture union, delayed union, and nonunion. Clin Orthop 355(S1): S22-S30.

20. Aro HT, Chao EY (1993) Bone-healing patterns affected by loading, fracture fragment stability, fracture type, and fracture site compression. Clin Orthop 293: 8-17.

21. Meschan I (1976) Fracture healing, complications from fractures, and methods of treatment from the radiologic standpoint. In synopsis of Analysis of Roentgen Signs in General radiology, WB Saunders, Philaelphia, pp: 49-54.

22. Brinker WO, Piermatti DL, Flo GL (1991) Handbook of Small Animal Orthopaedics and Fracture Treatment. Printed in the United States of America, phiadilphia London, pp: 72-79.

23. Doyle AJ, Manaster PJ (1994) Musculoskeletal trauma. In: Putman CE, Ravine CE, (Eds), Textbook of Diagnostic Imaging, 2nd (Edn.), WB Saunders, Philadelphia, pp: 1564-1576.
24. Ruedi TP, Buckley RE, Moran CG (2007) AO Principles of fracture Management.

25. Thelen M, Ritter G, Bucheler E (1993) Radioloic diagnosis of injuries to bones and joints. A guide for lologists and traumatologists, Thieme.

26. Lastayo PC, Winters KM, Hardy M (2003) Fracture healing: bone healing, fracture management, and current concepts related to the hand. J Hand Ther 16(2): 81-93.

27. McRae R, Esser M (2008) Practical fracture Treatment. Churchill Livingstone.

28. Lascombes P (2009) Flexible Intramedullary Nailing in Children $1^{\text {st }}$ Edition. Flexible intramedullary nailing in children lascombes.

29. Teot L (1987) Lenclouage centromedullaire elastic stable in I child. SOFCOT No. 28 French Science Expansion Workbook, Paris, pp: 71-90.

30. Winquist RA, Hansen ST (1980) Comminuted fractures of the femoral shaft treated by intramudllary nailing. Orthop Clin North Am 11(3): 633-648. 